University of Nebraska - Lincoln

DigitalCommons@University of Nebraska - Lincoln

1984

\title{
Kolmogorov Constants for CO2, Wind Velocity, Air Temperature, and Humidity Fluctuations Over a Crop Surface
}

S. B. Verma

University of Nebraska - Lincoln

Follow this and additional works at: https://digitalcommons.unl.edu/natrespapers

Part of the Natural Resources and Conservation Commons, Natural Resources Management and Policy Commons, and the Other Environmental Sciences Commons

Verma, S. B., "Kolmogorov Constants for C02, Wind Velocity, Air Temperature, and Humidity Fluctuations Over a Crop Surface" (1984). Papers in Natural Resources. 1193.

https://digitalcommons.unl.edu/natrespapers/1193

This Article is brought to you for free and open access by the Natural Resources, School of at DigitalCommons@University of Nebraska - Lincoln. It has been accepted for inclusion in Papers in Natural Resources by an authorized administrator of DigitalCommons@University of Nebraska - Lincoln. 


\title{
KOLMOGOROV CONSTANTS FOR $\mathrm{CO}_{2}$, WIND VELOCITY, AIR TEMPERATURE, AND HUMIDITY FLUCTUATIONS OVER A CROP SURFACE*
}

\author{
SHASHI B. VERMA and DEAN E. ANDERSON** \\ Institute of Agricultural and Natural Resources, University of Nebraska, Lincoln, Nebr., U.S.A.
}

(Received in final form 28 October, 1983)

\begin{abstract}
The Kolmogorov constants for $\mathrm{CO}_{2}$, wind velocity, air temperature, and humidity fluctuations were evaluated from measurements made over soybean and grain sorghum fields and found to be $0.78 \pm 0.11,0.49 \pm 0.08,0.70 \pm 0.15$, and $0.99 \pm 0.16$, respectively. These results are consistent with recent observations reported in the literature.
\end{abstract}

\section{Introduction}

Hicks and Dyer (1972) described a spectral density technique for determining turbulent fluxes. This technique utilizes known characteristics of the inertial subrange (see, e.g., Kaimal et al., 1972) and is particularly useful for measurements over the open ocean since it does not require explicit measurements of vertical velocity. Recently Large and Pond (1982) demonstrated the applicability of this approach in determining fluxes of sensible and latent heat from ships on the deep sea.

The flux computation technique mentioned above requires knowledge of the Kolmogorov constant for the fluctuating parameter with the appropriate spectral density value. The Kolmogorov constants for velocity and temperature fluctuations have been studied extensively. However, only a few studies have been reported on the Kolmogorov constant for humidity fluctuations. Except for one recent report (Ohtaki, 1982), the Kolmogorov constant for $\mathrm{CO}_{2}$ fluctuations has not been evaluated.

There is considerable interest in determining $\mathrm{CO}_{2}$ fluxes over the open ocean where the spectral density technique, using an appropriate value of the Kolmogorov constant, may be applied. In this paper, we present results of measurements of the Kolmogorov constants for $\mathrm{CO}_{2}$, wind velocity, air temperature, and humidity made over soybean and grain sorghum fields.

\footnotetext{
* Published as Paper No. 7255, Journal Series, Nebraska Agricultural Experiment Station. The work reported here was conducted under Regional Research Project 11-33 and Nebraska Agricultural Experiment Station Project 27-003.

** Associate Professor and Post Doctoral Research Associate, respectively, Center for Agricultural Meteorology and Climatology, Institute of Agriculture and Natural Resources, University of Nebraska, Lincoln, NE, U.S.A., 68583-0728.
}

Boundary-Layer Meteorology 28 (1984) 161-167. 0006-8314/84/0282-0161\$01.05.

(C) 1984 by D. Reidel Publishing Company. 


\section{Procedure}

\subsection{Measurements}

Studies reported here were conducted at the University of Nebraska Agricultural Meteorology Laboratory near Mead, Nebraska $\left(41^{\circ} 09^{\prime} \mathrm{N}, 96^{\circ} 30^{\prime} \mathrm{W}\right.$, altitude of $354 \mathrm{~m}$ above mean sea level). The Kolmogorov constants for velocity, humidity, and $\mathrm{CO}_{2}$ fluctuations are computed from measurements made at $2.25 \mathrm{~m}$ during August 20-September 2, 1981 over a soybean crop (zero plane displacement, $d \approx 0.45-0.50 \mathrm{~m}$ ) with an upwind fetch of at least $210 \mathrm{~m}$. The Kolmogorov constant for air temperature fluctuations was computed from measurements made during August 25-September 10, 1982 over a grain sorghum crop (zero plane displacement, $d \approx 0.75 \mathrm{~m}$ ) with an upwind fetch of $210 \mathrm{~m}$.

A drag anemometer was used to measure velocity fluctuations. This anemometer is described in Norman et al. (1976) and Redford et al. (1981). Air temperature fluctuations were measured with a fine-wire thermocouple described in Verma et al. (1979). A Lyman-alpha hygrometer (Buck, 1975, 1976; Redford et al., 1980) was used to measure humidity fluctuations. $\mathrm{CO}_{2}$ fluctuations were measured with a rapid response sensor designed and built at the Lawrence Livermore National Laboratory, California, under the direction of Dr Gail Bingham. This sensor is a dual wavelength differential infrared absorption spectrometer. It makes use of a strong $\mathrm{CO}_{2}$ absorption band centered at $4.27 \mu \mathrm{m}$ and a 'reference' band centered at $3.85 \mu \mathrm{m}$ in which absorption is minimal. The reference band is used to adjust for system instabilities arising from electronic drift, optical system degradation resulting from mirror contamination or variations in source emission. The difference in the sensor's output in the absorbed band and that in the reference band is directly proportional to the $\mathrm{CO}_{2}$ concentration. Further details on the mechanical and electronic features of this sensor are given in Bingham et al. (1978) and Bingham (1980).

A computer-controlled data acquisition system, consisting of a minicomputer, analog-to-digital convertors and a magnetic tape drive, was used to record all data. In 1981 the signals were electrically filtered by 8-pole Butterworth filters with a $6.25 \mathrm{~Hz}$ cutoff and sampled at $12.8 \mathrm{~Hz}$. In 1982 8-pole Butterworth filters with a $12.5 \mathrm{~Hz}$ cutoff were used and the sampling frequency was increased to $25 \mathrm{~Hz}$.

\subsection{Mathematical BaCKGROUND AND COMPUTATION}

Following the formulations outlined in Hicks and Dyer (1972) and Dyer and Hicks (1982), the spectral densities $S_{u}, S_{T}, S_{q}$, and $S_{c}$ for velocity, temperature, humidity, and $\mathrm{CO}_{2}$ fluctuations can be expressed as:

$$
\begin{aligned}
& \frac{n S_{u}(n)}{u_{*}^{2}}=\alpha_{u}(2 \pi k f)^{-2 / 3}\left(\phi_{m}-z / L\right)^{2 / 3} \\
& \frac{n S_{T}(n)}{T_{*}^{2}}=\alpha_{T}(2 \pi k f)^{-2 / 3} \phi_{H}\left(\phi_{m}-z / L\right)^{-1 / 3}
\end{aligned}
$$




$$
\begin{aligned}
& \frac{n S_{q}(n)}{q_{*}^{2}}=\alpha_{q}(2 \pi k f)^{-2 / 3} \phi_{w}\left(\phi_{m}-z / L\right)^{-1 / 3} \\
& \frac{n S_{c}(n)}{C_{*}^{2}}=\alpha_{c}(2 \pi k f)^{-2 / 3} \phi_{c}\left(\phi_{m}-z / L\right)^{-1 / 3}
\end{aligned}
$$

where $\phi_{m}, \phi_{H}, \phi_{w}$, and $\phi_{c}$ are the respective non-dimensional gradients; $f$ is normalized frequency $=[n(z-d)] / U, n$ is the natural frequency, $z$ is the elevation above ground, $U$ is the mean horizontal wind speed; $T_{*}=H /\left(\rho c_{p} u_{*}\right) ; q_{*}=E /\left(\rho u_{*}\right) ; C_{*}=F_{c} / u_{*} ; \rho$ is the air density; $c_{p}$ is the specific heat at constant pressure; $L$ is the moisture-corrected Monin-Obukhov length; $H, E$, and $F_{c}$ are fluxes of sensible heat, water vapor and $\mathrm{CO}_{2}$, respectively; $u_{*}$ is the friction velocity and $k$ is the von Karman constant (taken here to be 0.4). In deriving the above equations, the Kolmogorov hypothesis is followed. Incompressibility, stationarity, and horizontal homogeneity are assumed. Production and dissipation rates are assumed to be equal.

Dyer and Hicks (1970) have determined the following empirical relationships for $\phi_{m}$, $\phi_{H}$, and $\phi_{w}$ in unstable thermal stability:

$$
\phi_{m}=(1-16 z / L)^{-0.25}
$$

and

$$
\phi_{H}=\phi_{w}=(1-16 z / L)^{-0.50}
$$

Similarity of turbulence mechanisms of $\mathrm{CO}_{2}$, temperature and humidity was assumed, leading to:

$$
\phi_{c}=\phi_{H}=\phi_{w} .
$$

It is now possible to solve for the Kolmogorov constants using the relationships presented above. For a given $z / L$, corresponding values of $\phi_{m}, \phi_{H}, \phi_{w}$, and $\phi_{c}$ can be computed from Equations (5)-(7). Using these values in conjunction with the spectral density values $\left(S_{u}, S_{T}, S_{q}\right.$, and $\left.S_{c}\right)$, turbulent fluxes $\left(H, E, F_{c}\right)$, friction velocity $\left(u_{*}\right)$, natural frequency $(n)$, mean winds peed $(U)$, height of measurement $(z)$, and zero plane displacement $(d)$ in Equations (1)-(4), the Kolmogorov constants $\left(\alpha_{u}, \alpha_{r}, \alpha_{q}\right.$, and $\left.\alpha_{c}\right)$ can be calculated.

Spectral densities were computed by fast Fourier transform using a program from the Pennsylvania State University tape library called SAFFT (Parhami, 1971). Ten sets of spectra were analyzed using data recorded during thermally unstable conditions $(-0.1<z / L<-0.01)$. From individual spectra (at a given $z / L)$, three values of $n S(n)$ in the inertial subrange around $f=0.8-1.2$ were used to compute the Kolmogorov constants $(\alpha)$. Mean $\alpha$ values for a given $z / L$ are reported below. Fluxes of momentum, sensible heat, water vapor and $\mathrm{CO}_{2}$ were obtained from appropriate covariances. $\mathrm{CO}_{2}$ fluxes were corrected for the effects of water vapor exchange on the density of air (Webb et al., 1980). 

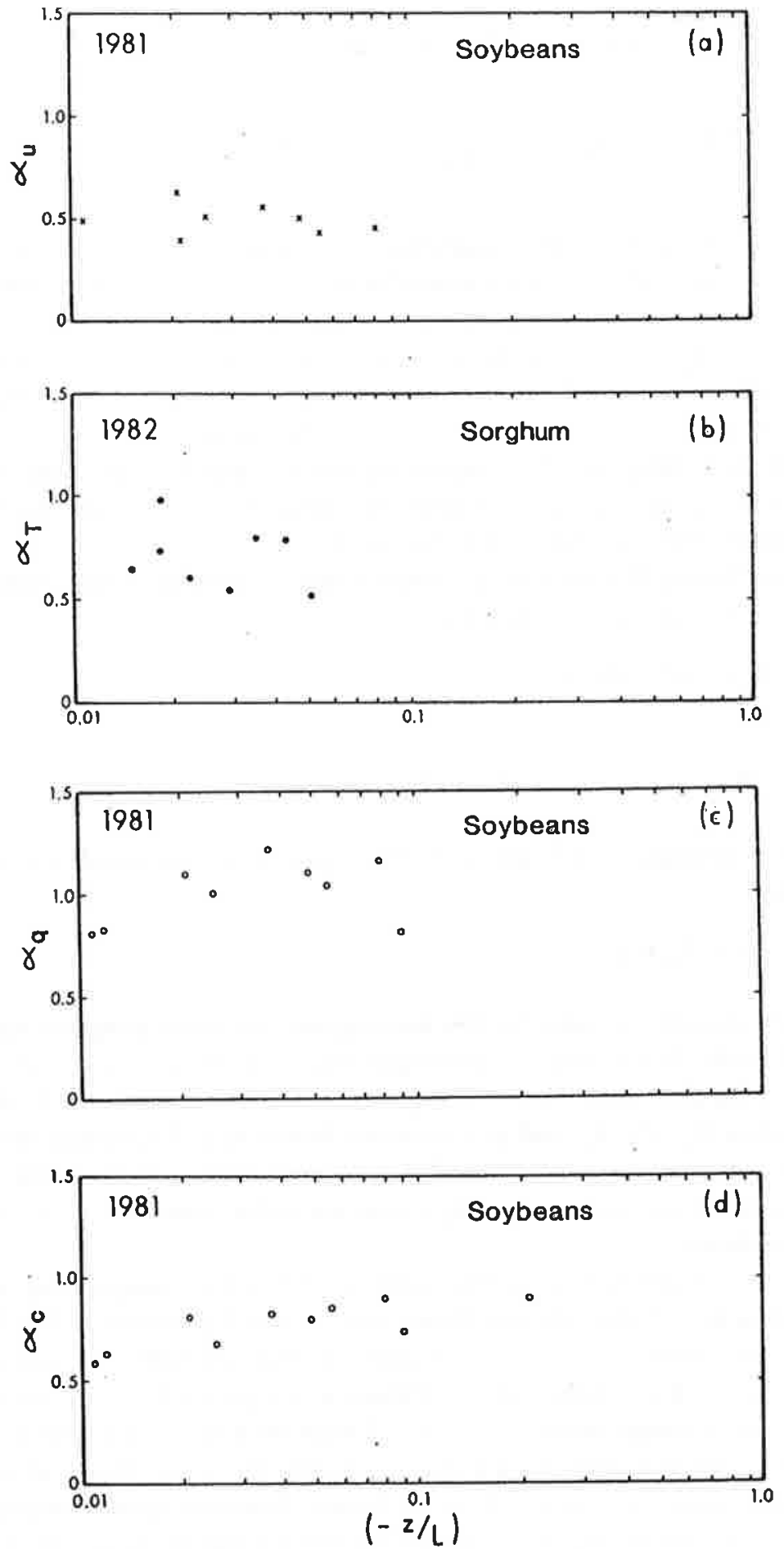

Fig. 1. Kolmogorov constants $\alpha_{u}, \alpha_{T}, \alpha_{q}$, and $\alpha_{c}$ plotted against thermal stability (z/L). 


\section{Results and Conclusions}

The values of the Kolmogorov constants obtained by using the procedure described above are presented in Figure 1 and Table I. In Figure $1, \alpha_{u}, \alpha_{T}, \alpha_{q}$, and $\alpha_{c}$ are plotted as functions of stability $(z / L)$. The values of $\alpha$ appear to be independent of $z / L$ in the range of stability considered here.

The values of the Kolmogorov constant for velocity $\left(\alpha_{u}\right)$ and temperature $\left(\alpha_{T}\right)$ fluctuations were found to be $0.49 \pm 0.08$ and $0.70 \pm 0.15$ (Table I). These compare closely with the values obtained by Wyngaard and Coté (1971), Kaimal et al. (1972), Hicks and Dyer (1972), and Dyer and Hicks (1982).

TABLE I

Values of Kolmogorov constants*

\begin{tabular}{llll}
\hline Fluctuation & $\begin{array}{l}\text { Kolmogorov } \\
\text { constant }\end{array}$ & Value & Source \\
\hline Velocity & $\alpha_{u}$ & $0.49 \pm 0.08$ & Present study \\
& & $0.52 \pm 0.05$ & Wyngaard and Coté (1971) \\
& & $0.50 \pm 0.05$ & Kaimal et al. (1972) \\
& & $0.54 \pm 0.03$ & Hicks and Dyer (1972) \\
& $\alpha_{T}$ & $0.59 \pm 0.01$ & Dyer and Hicks (1982) \\
Temperature & & $0.70 \pm 0.15$ & Present study \\
& & $0.82 \pm 0.10$ & Wyngaard and Coté (1971) \\
& & $0.68 \pm 0.02$ & Kaimal et al. (1972) \\
& & $0.99 \pm 0.16$ & Dyer and Hicks (1982) \\
Humidity & & $0.80 \pm 0.20$ & Present study \\
& & $0.88 \pm 0.26$ & Raupach (1978) \\
& & $0.76 \pm 0.03$ & Dyer and Hicks (1982) \\
& & $0.78 \pm 0.11$ & Present study \\
$\mathrm{CO}_{2}$ & $\alpha_{c}$ & $0.89 \pm 0.13$ & Ohtaki (1982) \\
& & &
\end{tabular}

- Note that $\alpha$ values vary as $k^{2 / 3}$. We chose $k=0.4$. If $k=0.37, \alpha$ values would be reduced by $5.1 \%$. If $k=0.41, \alpha$ values would be increased by $1.7 \%$.

The Kolmogorov constant for humidity fluctuations $\left(\alpha_{q}\right)$ was found to be $0.99 \pm 0.16$ (Table I), a little larger than those generally found in the literature (e.g., Paquin and Pond, 1971; Raupach, 1978; and Dyer and Hicks, 1982). Smedman-Hogstrom (1973), on the other hand, reported a value $(0.58 \pm 0.2)$, considerably lower than that found in this study and those in the literature mentioned above.

The Kolmogorov constant for $\mathrm{CO}_{2}$ fluctuations $\left(\alpha_{c}\right)$ was found to be $0.78 \pm 0.11$. This is in reasonable agreement with a value of $0.89 \pm 0.13$ reported by Ohtaki (1982), the only study known to us in which the Kolmogorov constant for $\mathrm{CO}_{2}$ has been evaluated. 


\section{Acknowledgements}

This study was supported by the Atmospheric Research Division of the National Science Foundation under Grants ATM-7901017 and ATM-8205431. Messrs. H. D. Earl and Dale Sandin provided excellent assistance in maintenance of instruments and data acquisition systems. Mr James Hines assisted in data computation. We wish to express our appreciation to Dr Gail Bingham and Mr Randall Kennedy for their assistance in identifying proper procedures for operating the rapid response $\mathrm{CO}_{2}$ sensor. Our thanks to Mrs Sharon Kelly for the stenographic work, and to Drs Norman J. Rosenberg and Kenneth G. Hubbard for their critical reviews of this paper.

\section{References}

Bingham, G. E.: 1980, 'A Miniature Rapid Response Sensor for Atmospheric Concentrations of Carbon Dioxide', Annual Report to DOE, Contract \#LLL/EV-81-65.

Bingham, G. E., Gillespie, C. H., and McQuaid, J. H.: 1978, 'Development of a Miniature, Rapid Response $\mathrm{CO}_{2}$ Sensor', Lawrence Livermore National Laboratory, Rept. UCRL-52440.

Buck, A.: 1975, 'Variable-Path Lyman-alpha Hygrometer Operating and Maintenance Manual 023032002, NCAR', Boulder, CO, 116 pp.

Buck, A.: 1976, 'The Variable Path Lyman-alpha Hygrometer and its Operating Characteristics', Bull. Amer. Meteorol. Soc. 57, 1113-1118.

Dyer, A. J. and Hicks, B. B.: 1970, 'Flux-Gradient Relationships in the Constant Flux Layer', Quart. J. Roy. Meteorol. Soc. 96, 715-721.

Dyer, A. J. and Hicks, B. B.: 1982, 'Kolmogoroff Constants at the 1976 ITCE', Boundary-Layer Meteorol. 22, 137-150.

Hicks, B. B. and Dyer, A. J.: 1972, 'The Spectral Density Technique for the Determination of Eddy Fluxes', Quart. J. Roy. Meteorol. Soc. 98, 838-844.

Kaimal, J. C., Wyngaard, J. C., Izumi, Y., and Coté, O. R.: 1972, 'Spectral Characteristics of Surface-Layer Turbulence', Quart. J. Roy. Meteorol. Soc. 98, 563-589.

Large, W. G. and Pond, S.: 1982, 'Sensible and Latent Heat Flux Measurements over the Ocean', J. Phys. Oceanog. 12, 464-482.

Norman, J. M., Perry, S. G., and Panofsky, H. A.: 1976, Measurement and Theory of Horizontal Coherence at a Two Meter Height, 3rd Symposium on Atmospheric Turbulence, Diffusion, and Air Quality, Raleigh, NC, AMS preprint, pp. 19-22.

Ohtaki, E.: 1982, "The Kolmogorov Constant for Carbon Dioxide in the Atmospheric Surface Layer over a Paddy Field', Boundary-Layer Meleorol. 23, 153-159.

Paquin, J. E. and Pond, S.: 1971, 'The Determination of the Kolmogoroff Constants for Velocity, Temperature, and Humidity Fluctuations from Second- and Third-Order Structure Functions', J. Fluid Mech, 50, 257-269.

Parhami, B.: 1971, 'Spectral Analysis by Fast Fourier Transform', Contributed computer program and write-up to the Computation Center, Dept. of Meteorology, The Pennsylvania State University, $24 \mathrm{pp}$.

Raupach, M. R.: 1978, 'Infrared Fluctuation Hygrometry in the Atmospheric Surface Layer', Quart. J. Roy. Meteorol. Soc. 104, 309-322.

Redford, T. G., Jr., Verma, S. B., and Rosenberg, N. J.: 1980, 'Humidity Fluctuations over a Vegetated Surface Measured with a Lyman-alpha Hygrometer and a Fine-Wire Thermocouple Psychrometer', $J$. Amer. Meteorol. 19, 860-867.

Redford, T. G., Jr., Verma, S. B., and Rosenberg, N. J.: 1981, 'Drag Anemometer Measurements of Turbulence over a Vegetated Surface', J. Appl. Meteorol. 20, 1222-1230.

Smedman-Högstróm, A.: 1973, 'Temperature and Humidity Spectra in the Atmospheric Surface Layer', Boundary-Layer Meteorol. 3, 329-347. 
Verma, S. B., Motha, R. P., and Rosenberg, N. J.: 1979, 'A Comparison of Temperature Fluctuations Measured by a Microbead Thermistor and a Fine Wire Thermocouple over a Crop Surface', Agr. Meteorol. 20, 281-289.

Webb, E. K., Pearman, G. I., and Leuning, R.: 1980, 'Correction of Flux Measurements for Density Effects Due to Heat and Water Vapour Transfer', Quart. J. Roy. Meteorol. Soc. 106, 85-100.

Wyngaard, J. C. and Coté, O. R.: 1971, 'The Budgets of Turbulent Kinetic Energy and Temperature Variance in the Atmospheric Surface Layer', J. Atmos. Sci. 28, 190-201. 


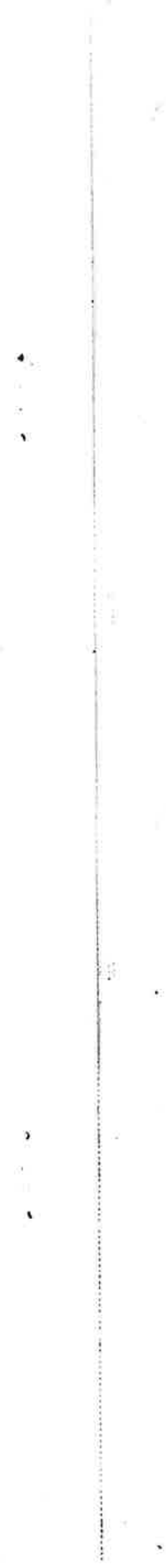

